\title{
La Respuesta Jurídica de la Unión Europea ante las Migraciones Climáticas. ¿Es Suficiente? *
}

\section{The European Union Legal Response to Climate Migration. Is It Enough?}

SANTIAGO SALVADOR GIMENO

Universidade de Vigo, Campus da Auga. Rúa Canella da Costa da Vela, 12, 32004 Ourense, España ssalvador@uvigo.es

@) (®) Este artículo está sujeto a una licencia “Creative Commons ReconocimientoNo Comercial" (CC-BY-NC).

DOI: $\underline{\text { https://doi.org/ 10.24197/ree.79.2022.115-138 }}$

Resumen: Pese a la existencia de algunos esfuerzos que se vienen desarrollando a nivel internacional, europeo y nacional a la hora de reducir la emisión de gases efecto invernadero y abordar los efectos negativos derivados del cambio climático, se prevé que el avance del mismo origine desplazamientos poblacionales tanto a nivel interno como a nivel transfronterizo en un futuro próximo. Es probable que ello intensifique los flujos migratorios hacia países europeos principalmente provenientes de las rutas del mediterráneo occidental, oriental y central, así como del atlántico desde la zona del norte de África. Ante esta circunstancia conviene reflexionar si el Derecho de la Unión Europea proporciona soluciones adecuadas que se adapten a esta realidad incipiente proporcionando un marco de protección para esta nueva categoría de migrantes, o si, por el contrario, es preciso adoptar un nuevo marco normativo que aborde de forma específica ésta cuestión.

Palabras clave: Cambio Climático; Migrantes Climáticos; Refugiados; Sistema Europeo Común de Asilo (SECA); Derechos Humanos; Principio de no devolución; prohibición de tratos inhumanos o degradantes.

Abstract: Despite the existence of some efforts that are developing at the international, European and national levels in order to reduce greenhouse gases emissions, it is expected that Climate Change will cause both internally and cross-border population displacements in the near future. This is likely to intensify migratory flows to European countries mainly from the western, eastern and central Mediterranean routes, as well as from the Atlantic route from the North African area. Given this circumstance, it is convenient to reflect on whether European Union law provides adequate solutions that adapt to this incipient reality by providing a protection framework for this new category of migrants, or whether, on the contrary, it is necessary to adopt a new regulatory framework that addresses specifically this issue.

Este trabajo se ha realizado en el marco de de las ayudas postdoctorales convocadas por la Xunta de Galicia mediante la Orden de 28 de mayo de 2019. 
Keywords: Climate Change; Climate Migrants; Refugees; Common European Asylum System (CEAS); Human Rights; Principle of non-refoulement; prohibition of inhuman or degrading treatment.

\section{INTRODUCCIÓN}

Como ha anticipado la Organización Internacional para las Migraciones (OIM $)^{1}$, es probable que en un futuro cercano millones de personas se vean forzadas a migrar, tanto a nivel interno, como a nivel transfronterizo, como consecuencia de los efectos negativos derivados del cambio climático, entre ellos sequías, desertificación, subida del nivel del mar, inundaciones, fenómenos extremos, pérdida de medios de vida o contaminación de agua potable.

Estos fenómenos responden a causas antropogénicas, y, principalmente, a las emisiones de Gases Efecto Invernadero (GEI). Una aplicación del Principio de las Responsabilidades Comunes, pero diferenciadas $^{2}$ al panorama de las migraciones climáticas podría hacernos pensar en la necesidad de una mayor implicación por parte de los países (o grupos de países) desarrollados más contaminantes a la hora de abordar esta cuestión y de prestar soluciones y apoyo directo los nacionales de terceros Estados -por lo general, menos desarrolladosque se ven forzados a migrar como consecuencia de los efectos negativos derivados del cambio climático.

Es cierto que, por el momento, en la práctica se han encontrado dificultades a la hora de lograr atribuir una responsabilidad concreta e individualizada a un país - o grupo de países- sobre el cambio climático y sus efectos (y, en particular, sobre las migraciones que éste ocasiona sobre los habitantes de aquellos Estados más vulnerables y que se encuentran intensamente expuestos al mismo). Ello fundamentalmente es debido a la existencia de una pluralidad de actores contaminantes en el panorama internacional -que contribuyen en mayor o en menor medida al calentamiento global- y a las dificultades presentes a la hora de

\footnotetext{
${ }^{1}$ Que prevé 200 millones de desplazados por causa de los efectos derivados del cambio climático para el 2050.

2 Principio reconocido en numerosos textos y acuerdos internacionales en materia de medio ambiente, como la Declaración de Rio sobre el Medio Ambiente y el Desarrollo de 1992 o el Acuerdo de Paris, alcanzado en 2015 en el ámbito del Convenio Marco de las Naciones Unidas sobre el Cambio Climático (en la COP 21).
} 
demostrar de forma nítida el nexo de causalidad existente entre las acciones u omisiones concretas de un Estado o grupos de Estados y los daños que sufren aquellas personas que se ven obligadas a desplazarse como consecuencia de los efectos devastadores derivados del cambio climático -nos encontramos ante lo que se denominan "responsabilidades difusas"-. Si bien, de cara a superar estos obstáculos, la literatura científica ha propuesto diversas soluciones alternativas, como, por ejemplo, la concreción de la responsabilización de los diferentes Estados en función de su respectiva cuota histórica (\%) de emisión de GEI desde los niveles preindustriales ${ }^{3}$.

En relación a la contribución de la UE al avance del Cambio Climático, si bien se están registrando algunos avances a la hora de frenar el calentamiento global, y su voluntad política parece ir, en parte, encaminada en esta dirección ${ }^{4}$, no es menos cierto que es el tercer emisor de Gases Efecto Invernadero, por detrás de China y de EEUU (representando un 7\% de las emisiones mundiales) ${ }^{5}$.

Por otro lado, los países que están sufriendo con una mayor intensidad los impactos que se derivan del cambio climático (y, los más vulnerables a sus efectos), son, paradójicamente -por norma general-

${ }^{3}$ Felipe Pérez, Beatriz, et al., (2019), "Migraciones climáticas: el papel de los derechos humanos para superar el persistente vacío jurídico” Revista Latinoamericana de Derechos Humanos, 30 (1), p. 33.

${ }^{4}$ Vid., por ejemplo, las recientes iniciativas de El Pacto Verde Europeo -Comunicación de la Comisión COM (2019) 640 final-, así como la propuesta de una «Ley del Clima Europea»-COM (2020) 80 final-.

${ }^{5}$ UNEP (2020), Emissions Gap Report, p. 6. Un estudio sobre la contribución de las Empresas de la Unión Europea al cambio climático y, en particular, a las migraciones climáticas puede encontrarse en Felipe Pérez, Beatriz (2020), El papel del Sector Privado Europeo ante las migraciones climáticas Una propuesta de debida diligencia. Como movimiento crítico con las políticas adoptadas por la UE en materia de Cambio Climático cabe destacar la presentación de un recurso por parte de 37 particulares originarios tanto de países de la UE como de terceros Estados ante el Tribunal de Justicia de la Unión Europea contra el Consejo de la Unión Europea y el Parlamento de la Unión Europea Vid. Recurso interpuesto el 23 de mayo de 2018 - Carvalho y otros/Parlamento y Consejo (Asunto T-330/18). Dicho recurso fue inadmitido en primera instancia por el Tribunal General (sala Segunda) mediante Auto de 8 de mayo de 2019, y, el subsiguiente recurso de casación presentado fue desestimado en la Sentencia del Tribunal de Justicia (Sala Sexta) de 25 de marzo de 2021 Armando Carvalho y otros contra Parlamento Europeo y Consejo de la Unión Europea Asunto C-565/19 P. 
aquellos económicamente menos desarrollados y que menos han contribuido al calentamiento global ${ }^{6}$.

Por todo ello, ante la creciente posibilidad de que en un futuro cercano los habitantes de dichos Estados se vean obligados a desplazarse fuera de sus fronteras (al volverse extremadamente difíciles -o incluso imposibles- sus condiciones de vida como consecuencia de los impactos derivados del cambio climático) es preciso articular una respuesta eficaz y anticipada dirigida a brindarles una protección adecuada.

A este respecto, vamos a estudiar las -limitadas- soluciones que ofrece actualmente el Derecho de la UE a esta problemática, para, posteriormente analizar los desafíos y vacíos existentes que han de colmarse de cara a brindar una protección eficaz a los desplazados climáticos provenientes de terceros países.

\section{EL PAPEL DE LA UE EN LAS POLÍTICAS EN MATERIA DE MIGRACIÓN Y ASILO Y SU LIMITADA RESPUESTA A LAS MIGRACIONES CLIMÁTICAS}

\section{1. Las Competencias de la UE en Materia de Migración y Asilo y su evolución:}

Las competencias en Políticas en materia de migración y asilo entre la UE y los Estados Miembros son compartidas, encargándose la primera de desarrollar una política común en materia de asilo, protección subsidiaria y protección temporal para aquellos nacionales de terceros países que necesiten protección internacional, así como una política común de inmigración destinada a garantizar (...) una gestión eficaz de

\footnotetext{
${ }^{6}$ Así, por ejemplo, como se puede leer en una noticia publicada recientemente en la web de la FAO, más de 13 millones de personas en partes de Etiopía, Kenia, Somalia, Uganda y Yibuti enfrentan una escasez crónica de agua y alimentos, entre otras razones por el cambio climático. Información disponible en: http://www.fao.org/inaction/agronoticias/detail/es/c/508442/ (último acceso: 02.06.2021). Sin olvidarnos tampoco de los habitantes de aquellos pequeños insulares de escasa altitud, como Tuvalu o Kiribati, que están en riesgo de desaparecer por hundimiento como consecuencia de la subida del nivel del mar, generada por los efectos del cambio climático.
} 
los flujos migratorios (...), así como una prevención de la inmigración ilegal ${ }^{7}$.

Haciendo un breve resumen de la evolución histórica en la atribución de las mencionadas competencias, baste apuntar que con el Tratado de Maastricht (1992) la UE comienza a tener un cierto papel a la hora de coordinar dichas políticas, un rol que adquirirá una mayor relevancia con el Tratado de Ámsterdam (en vigor desde 1999) ${ }^{8}$, y que encontrará su punto más álgido tras el Tratado de Lisboa (en vigor desde 2009). En este iter se aprecia una cierta disminución progresiva de los elevados poderes iniciales del Consejo de la UE -y, por ende, de los Estados Miembros (a los que representa)-, no solo a nivel general, sino también en esta materia, que culmina con la equiparación del Parlamento al Consejo en materia legislativa ${ }^{9}$.

Pese a la mencionada evolución, la capacidad de actuación de la UE en estas materias continúa en cierto modo restringida por las posiciones de los Estados Miembros, que mayoritariamente han puesto el foco en contener la migración irregular más que en facilitar desplazamientos seguros, regulares y ordenados, lo cual limita, en parte, la eficacia de las políticas comunitarias dirigidas a lograr una verdadera integración en este punto $^{10}$. Asimismo, en esta misma dirección, pese a los intentos de armonización perseguidos por la UE a través del SECA, en la práctica se aprecia una falta de homogeneización, persistiendo importantes diferencias entre los sistemas nacionales de asilo de los distintos estados miembros ${ }^{11}$.

\footnotetext{
${ }^{7}$ Vid. arts.78-79 del Tratado de Funcionamiento de la Unión Europea (TFUE).

8 Momento en el que se considera atribuida a la UE la competencia en materia migratoria y en la que ésta comienza a desarrollar el Sistema Europeo Común de Asilo (SECA).

${ }^{9}$ Liguori, Chiara (2021), “The response of the European Union to human mobility in the context of climate change” Refugee Law Initiative Working Paper 54, p. 23.

${ }^{10}$ Liguori, Chiara (2021), “The response of ...” op. cit., p. 17.

11 Vid. Inter Alia, Pérez Villalobos, María Concepción (2017), “La Crisis de los Refugiados y el Derecho de Asilo en la Unión Europea” Anales de Derecho, 1, p. 8.
} 


\section{2. El Sistema Europeo Común de Asilo (SECA) y la Difícil Aplicación de la Directiva sobre Requisitos a los Migrantes Climáticos}

Como hemos avanzado, la UE trabaja en el desarrollo del SECA desde 1999, persiguiendo la adopción de normas comunes mínimas destinadas a establecer un procedimiento común y un estatuto uniforme para las personas a las que se conceda asilo ${ }^{12}$ en toda la Unión.

Dentro de los principales textos normativos que componen el SECA $^{13}$, destaca la Directiva 2011/95/UE del Parlamento Europeo y del Consejo de 13 de diciembre de $2011^{14}$ (también denominada Directiva sobre Requisitos), que concreta los motivos que dan lugar a la concesión de protección internacional, estableciendo dos categorías de beneficiarios de la misma: los "refugiados" y los destinatarios de la denominada "protección subsidiaria”.

${ }^{12}$ El Derecho de Asilo aparece expresamente reconocido en el artículo 18 de la Carta de los Derechos Fundamentales de la Unión Europea.

${ }^{13}$ Que, junto con la Directiva sobre Requisitos, también está integrado por la Directiva sobre Procedimientos de Asilo (que establece las normas de todo el proceso de solicitud); la Directiva sobre Condiciones de Acogida (que persigue garantizar asistencia sanitaria, alimenticia y alojamiento a los solicitantes de asilo mientras esperan una decisión que resuelva su solicitud); el Reglamento de Dublín (que fija los criterios para determinar qué Estado miembro será el responsable para examinar en cada caso las diferentes solicitudes) y el Reglamento Eurodac (que crea una base de datos destinada a recoger las impresiones dactilares de los solicitantes de asilo).

${ }^{14}$ Por la que se establecen normas relativas a los requisitos para el reconocimiento de nacionales de terceros países o apátridas como beneficiarios de protección internacional. Conviene señalar que en el 2016 se presentó una propuesta para sustituir dicha Directiva por un Reglamento con el fin de alcanzar un enfoque más armonizado de la aplicación de su contenido por parte de los Estados Miembros. Vid. COM/2016/0466 final Propuesta de Reglamento del Parlamento Europeo y del Consejo por el que se establecen normas relativas a los requisitos para el reconocimiento de nacionales de terceros países o apátridas como beneficiarios de protección internacional, a un estatuto uniforme para los refugiados o para las personas con derecho a protección subsidiaria y al contenido de la protección concedida y por el que se modifica la Directiva 2003/109/CE del Consejo, de 25 de noviembre de 2003, relativa al estatuto de los nacionales de terceros países residentes de larga duración. Dicha propuesta de Reglamento ha sido nuevamente apoyada por la Comisión en el marco del Nuevo Pacto sobre Migración y Asilo. Vid. Comunicación de la Comisión relativa al Nuevo Pacto sobre Migración y Asilo COM (2020) 609 final. 
En relación al primer grupo, el artículo 2.d) de la Directiva sobre Requisitos recoge un concepto de "refugiado"" muy similar al contemplado por el artículo 1.A) de la Convención de Ginebra de 1951, lo que dificulta en gran medida la incardinación dentro del mismo de aquellas personas provenientes de terceros Estados que se ven obligadas a desplazarse como consecuencia de los efectos derivados del cambio climático.

En este sentido, para que se le aplique el estatuto de "refugiado" a un individuo, es preciso que (además de encontrarse fuera de su país de origen) tenga fundados temores de ser perseguido por una de las causas concretas enumeradas en dicho precepto: raza, religión, nacionalidad, opiniones políticas o pertenencia a determinado grupo social. Sin embargo, como entiende la doctrina mayoritaria ${ }^{16}$, la propia ACNUR $^{17}$, y como también han reconocido diversos Tribunales Nacionales de terceros

${ }^{15}$ Definido como un nacional de un tercer país que, debido a fundados temores a ser perseguido por motivos de raza, religión, nacionalidad, opiniones políticas o pertenencia a determinado grupo social, se encuentra fuera del país de su nacionalidad y no puede o, a causa de dichos temores, no quiere acogerse a la protección de tal país, o un apátrida que, hallándose fuera del país donde antes tuviera su residencia habitual por los mismos motivos que los mencionados, no puede o, a causa de dichos temores, no quiera regresar a él.

${ }^{16}$ Vid. inter alia, Prieur, Michel s.f., Draft Convention on the International Status of Environmentally-Displaced Persons, p. 3. Disponible en: https://unfccc.int/files/adaptation/groups_committees/loss_and_damage_executive_ committee/application/pdf/prieurconvention_on_the_international_status_of_environmentally.pdf (último acceso: 21.06.2021).

17 ACNUR entiende que el cambio climático como razón del desplazamiento, por si sola, no justifica la aplicación del estatuto de "refugiado", siendo preciso, para ello, que, de forma conexa, concurra alguna de las causas y requisitos que se incluyen expresamente en la definición de "refugiado", lo cual normalmente tendrá lugar en aquellos casos en los que el cambio climático interaccione con situaciones de conflictos y violencia. Cfr. ACNUR (UNHCR) (2020), Legal considerations regarding claims for international protection made in the context of the adverse effects of climate change and disasters, 1 October 2020,p. 6 (párrafo 11). Disponible en: https://www.refworld.org/docid/5f75f2734.html. Ello no es extraño que pueda llegar a darse en la práctica, pensemos que el agotamiento de recursos y el empobrecimiento de las tierras puede devenir en importantes crisis socioeconómicas y políticas que acaben desencadenando conflictos, guerras y persecuciones. Un estudio interesante sobre estas conexiones entre cambio climático, conflictos y desplazamientos forzados puede encontrarse en: Abel, Guy, et al., (2019): “Climate, conflict and forced migration” Global Environmental Change, Volume 54, 2019, pp. 239-249. 
Estados (en Australia y Nueva Zelanda) ${ }^{18}$, en el caso particular de las personas que se desplazan de su país de origen como consecuencia de los impactos derivados del cambio climático, es difícil considerar que lo hacen porque temen ser "perseguidos" por una de las causas enunciadas en el precepto. Es cierto que podría intentar argumentarse -si bien, con dificultades ${ }^{19}$ - que los impactos derivados del cambio climático constituyen una forma de "persecución" contra las personas que los sufren y que, por ello, se ven forzadas a migrar ${ }^{20}$, pero más difícil sería defender la idea de que los efectos negativos derivados de dicha persecución van dirigidos expresamente contra ellas precisamente por formar parte un grupo social particular o por otra causa discriminatoria de las enumeradas en el artículo 2.d) (y desarrolladas en el artículo 10) de la Directiva ${ }^{21}$.

Por otro lado, si comparamos la definición de "refugiado" recogida en el texto comunitario con la contemplada en otros instrumentos normativos desarrollados en otras regiones geográficas, podemos observar cómo, por ejemplo, en el caso de la Convención de Addis Abeba de la Organización para la Unidad Africana de 1969 o en la Declaración de Cartagena de 1984 en América Latina, se opta por un concepto más amplio que, siguiendo una interpretación extensiva podría

18 Vid. RRT Case No. 0907346, [2009] RRTA 1168, Australia: Refugee Review Tribunal, 10 December 2009; así como The Supreme Court of New Zealand: SC 7/2015 [2015] NZSC 107.

${ }^{19}$ Especialmente si nos fijamos en la conceptualización que adopta la Unión Europea, dado que la Directiva en su artículo 9.1 parece acotar todavía más lo que ha de entenderse como "actos de persecución" (si lo comparamos con la previsión genérica contemplada en la Convención de Ginebra de 1951), al exigir su necesaria vinculación con violaciones graves de los derechos humanos fundamentales.

20 En cuanto al "perseguidor", siguiendo esta misma línea interpretativa extensiva podría intentar identificarse en este sentido a algún Estado contaminante concreto, a la comunidad internacional en su conjunto, a las empresas que emiten más gases efecto invernadero a la atmósfera.

${ }^{21}$ En efecto, los efectos del cambio climático son indiscriminados, y, si bien es cierto que son generalmente los habitantes de los países menos desarrollados y más vulnerables los que generalmente los sufren de forma más intensa, ello no responde a la voluntad de un "perseguidor" que quiera causarles un daño por motivos discriminatorios. McAdam, Jane (2010), "El Desplazamiento Provocado por el Cambio Climático y el Derecho Internacional”. Evento paralelo al Diálogo del Alto Comisionado sobre los desafíos en materia de protección 8 de diciembre de 2010, Palacio de las Naciones, p.2. Faltaría, pues, en todo caso, el elemento volitivo o discriminatorio que había de motivar la persecución. 
facilitar -si bien, de forma algo forzada- la inclusión dentro del mismo de los migrantes climáticos. Así, dentro de las causas de desplazamiento de los "refugiados", ambos textos normativos añaden el acaecimiento de un evento particularmente perturbador del "orden público"22. En este sentido, podría intentar argumentarse que las consecuencias del cambio climático -como las sequías, la falta de agua potable o la degradación de tierras y pérdidas de medios de vida- pueden llegar a desencadenar una perturbación del orden público que fuerce a los individuos a huir de sus países de origen.

Una vez analizadas las dificultades existentes a la hora de lograr que los migrantes climáticos puedan beneficiarse del estatuto de refugiado de conformidad con la Directiva sobre Requisitos, conviene estudiar la posibilidad de considerarlos incluidos dentro de la llamada "protección subsidiaria”, donde parece que cuentan con un margen algo mayor de maniobra. Para que un nacional de un tercer Estado pueda beneficiarse de dicha protección deben existir motivos fundados para creer que, en caso de que regresase a su país de origen, se enfrentaría a un riesgo real de sufrir un daño grave ${ }^{23}$. Aquí cabría preguntarse si los daños ocasionados por el cambio climático estarían subsumidos dentro del concepto de daño grave. A este respecto, podemos decir que dentro de los supuestos constitutivos de daño grave enumerados por el artículo 15 de la Directiva no se incluyen expresamente los daños medioambientales $^{24}$-ni, en particular, los daños ocasionados por el cambio climático-. Pese a ello, estimamos que la letra b) de dicho precepto, que considera comprendidos los tratos inhumanos o degradantes dentro de los casos de daños graves, sí que podría llegar a dar pie a la aplicación de la "protección subsidiaria" a determinados casos de desplazados climáticos -principalmente, a los que revistan de una mayor gravedad-, siempre que se parta de una interpretación amplia o extensiva que entienda que los efectos derivados del cambio climático pueden llegar a exponer a las personas que los sufren más intensamente -

${ }^{22}$ Vid. Convención de Addis Abeba de 1969 (art. 1) y Declaración de Cartagena de 1984 (conclusión $n^{\circ} 3$ )

${ }^{23}$ Vid. Art. 2.f) de la Directiva 2011/95/UE sobre Requisitos.

${ }^{24}$ Sin embargo, es de destacar que la Comisión sí discutió sobre la posible integración de los mismos, por lo que es posible que se produzcan evoluciones en esta línea. Vid. Espósito, Carlos y Torres Camprubí, Alejandra (2012), "Cambio Climático y Derechos Humanos: El desafío de los 'nuevos refugiados"” Revista de Derecho Ambiental de la Universidad de Palermo, p. 19. 
y que, por ello, se ven forzadas a migrar- a tratos inhumanos o degradantes, y, por tanto a un riesgo real de sufrir un daño grave ${ }^{25}$.

Cabe destacar que, a pesar de las limitaciones existentes en la práctica a la hora de aplicarles la "protección subsidiaria” establecida por la Directiva, algunos países de la Unión Europea, como Finlandia, Suecia, Chipre e Italia sí que han contemplado en su derecho interno algunas disposiciones legales destinadas a ofrecer dicha protección a los migrantes climáticos ${ }^{26}$.

\section{3. La Directiva de Protección Temporal. Una Posible Solución Limitada}

La Directiva 2001/55/CE del Consejo, de 20 de julio de $2001^{27}$ (también denominada "Directiva de Protección Temporal”) supone un procedimiento de carácter excepcional que proporciona una protección temporal e inmediata ${ }^{28}$ para los desplazados de terceros Estados cuando se produzcan situaciones de "afluencia masiva". El artículo 2.d) define este término como "la llegada a la Comunidad de un número importante de personas desplazadas, procedentes de un país o de una zona geográfica determinada”. Si bien, no especifica si se requiere que estos desplazamientos tengan lugar, bien de forma súbita (pensemos, por ejemplo, en eventos extremos, que pueden verse incrementados por la acción del cambio climático), bien de forma gradual (por ejemplo, las migraciones progresivas ocasionadas como consecuencia de la paulatina

${ }^{25}$ Esta cuestión relativa al no sometimiento a tratos inhumanos o degradantes y su relación con los migrantes climáticos será tratada con mayor profundidad en el epígrafe relativo al principio de non-refoulement o de no devolución.

26 The Greens in the European Parliament (2013), Position Paper Climate Change, Refugees and Migration (p. 12). Disponible en: https://europeangreens.eu/sites/europeangreens.eu/files/news/files/Greens\%20EFA \%20-\%20Position\%20Paper\%20\%20Climate\%20Change\%20Refugees\%20and\%20Migration.pdf (último acceso: 02.06.2021). Si bien, la aplicación de la mayoría de estos mecanismos de tutela desarrollados a nivel nacional fue suspendida durante la crisis de los Refugiados de 2015.

${ }^{27}$ relativa a las normas mínimas para la concesión de protección temporal en caso de afluencia masiva de personas desplazadas y a medidas de fomento de un esfuerzo equitativo entre los Estados miembros para acoger a dichas personas y asumir las consecuencias de su acogida.

28 Protección que consistirá principalmente en el otorgamiento de un permiso de residencia que será expedido por las autoridades de un Estado miembro. 
subida del nivel del mar, incrementada como resultado del deshielo de los glaciares). Por lo que, en una primera aproximación, no podemos excluir ambos tipos de movimientos poblacionales ${ }^{29}$.

Entrando en la delimitación del concepto de "personas desplazadas" -esto es, aquellas que podrán acogerse a la protección de la Directiva-, el artículo 2.c) las define como aquellos extranjeros que se encuentran fuera de su país y cuyo regreso en condiciones seguras y duraderas sea imposible debido a la situación existente en el mismo (una circunstancia que podría concurrir perfectamente en el caso de los migrantes climáticos -pensemos en los ciudadanos de un país extranjero que se ha tornado en gran parte inhabitable como consecuencia de fuertes inundaciones $\mathrm{u}$ otros eventos extremos asociados al cambio climático- $)^{30}$.

Sin embargo, a continuación, dicho precepto concreta -si bien, de forma no taxativa- las principales causas determinantes de la imposibilidad de que éstas personas puedan regresar a su país de origen, haciendo énfasis en aquellas que dan lugar a la protección bajo el estatuto de "refugiado", y, en particular: la huida de zonas de conflicto armado o de violencia permanente; y el peligro grave de verse expuesto a una violación sistemática o generalizada de los derechos humanos. En relación a este último supuesto cabría reflexionar acerca de si los efectos del cambio climático pueden llegar a violar los Derechos Humanos de los habitantes de los países más vulnerables que sufren sus efectos ${ }^{31}$. Cuestión ésta no baladí y sobre la que ha abierto la puerta recientemente el Comité de los Derechos Humanos de la $\mathrm{ONU}^{32}$, que años atrás ya había comenzado a reconocer de forma expresa -en la misma dirección

29 Será en cualquier caso el Consejo, a propuesta de la Comisión, el que decida (por mayoría cualificada) acerca de la existencia de una afluencia masiva de personas desplazadas y el que determine la aplicación en todos los Estados miembros de dicha protección temporal (art. 5).

${ }^{30}$ Vid., este mismo sentido, De Moor, Nicole y Cliquet, An (2012), Environmenyal Displacement: a New Challenge for European Migration Policy, p.9.

31 De hecho, algunos Estados -como Finlandia- propusieron la inclusión de los "refugiados climáticos" de forma expresa en el artículo 2.c) de la Directiva dentro de esta categoría de "violaciones sistemáticas o generalizadas de Derechos Humanos". Sin embargo, dicha propuesta no fue finalmente adoptada debido a la oposición de otros Estados. Vid. Espósito, Carlos y Torres Camprubí, Alejandra (2012), “Cambio Climático y...” op. cit., p. 21.

${ }^{32}$ Vid. CCPR/C/127/D/2728/2016 Dictamen de 23 de septiembre de 2020 aprobado por el Comité de Derechos Humanos a tenor del artículo 5, párrafo 4, del Protocolo Facultativo, respecto de la comunicación núm. 2728/2016 (párrafo 9.11). 
que el Relator Especial sobre los derechos humanos y el medio ambiente $^{33}$ - cómo el cambio climático puede tener efectos adversos en el efectivo goce de los Derechos Humanos (principalmente el derecho a la vida, a la salud, a la alimentación, al agua y a la vivienda) ${ }^{34}$.

Por todo ello, como ha sido analizado, podemos concluir que, si llevamos a cabo una interpretación extensiva de la Directiva, podría considerarse que la protección que brinda incluye a las personas que se ven forzadas a migrar como consecuencia de los efectos derivados del cambio climático. No obstante, dado su carácter temporal, ofrece una protección limitada que no llega a constituir una solución definitiva para aquellos migrantes climáticos que se vean obligados a migrar permanentemente $^{35}$. Pensemos en aquellos países que es probable que en un futuro próximo desaparezcan como consecuencia de la subida del nivel del mar y en los que -en tal caso- es posible que no exista posibilidad de retorno de sus nacionales ${ }^{36}$. En estos supuestos, la protección máxima de 1 año (prorrogable hasta otro año más) que -con carácter general- ofrece la Directiva a las personas desplazadas no sería suficiente.

Conviene indicar que recientemente, en el marco del nuevo Pacto sobre Migración y Asilo, la Comisión Europea ha presentado una Propuesta de Reglamento dirigido a ofrecer una protección inmediata situaciones de crisis y de fuerza mayor en el ámbito de la migración y el asilo $^{37}$, cuya aprobación derogaría la Directiva de Protección Temporal. En relación a esta nueva Propuesta, la doctrina ha señalado que, si bien la

33 Vid. Informe anual del Relator Especial sobre los derechos humanos y el medio ambiente A/HRC/31/52 de 2016.

34 Vid. Resoluciones del Consejo de Derechos Humanos 7/23 (2008); 10/14 (2009); 18/22 (2011); 26/27 (2014); 29/15 (2015); 32/33 (2016).

35 Vid. Leal Arcas, Rafael (2012), “Climate migrants: Legal options” International Conference on Emerging Economies - Prospects and Challenges (ICEE-2012). Procedia - Social and Behavioral Sciences 37, p. 93. Asimismo, Vid. López Ramón, Fernando (2017), "Los Derechos de los Emigrantes Ecológicos”. Cuadernos Manuel Jiménez Abad, p. 12 y Martín Pascual, Elena (2018), "Migraciones causadas por...” op. cit., pp. 23-24.

${ }^{36}$ En este mismo sentido Vid. Amado Gomes, Carla (2014), "Migrantes climáticos Para além da Terra Prometida”, Congresso de Direitos Humanos, 20 a 22 de Novembro de 2013, p. 5. Asimismo, Vid. Martín Pascual, Elena (2018), “Migraciones causadas por..." op. cit., p. 24.

37 Propuesta de Reglamento del Parlamento Europeo y del Consejo relativo a las situaciones de crisis y de fuerza mayor en el ámbito de la migración y el asilo COM (2020) 613 final. 
misma establece un procedimiento y unos plazos más simplificados y ofrece una mayor protección a las personas seleccionadas, establece unos criterios de selección más estrictos ${ }^{38}$. Ello complicaría su aplicación a los migrantes climáticos ${ }^{39}$, que encontrarían dificultades para entrar dentro de la categoría de "personas desplazadas que, en su país de origen, corran un riesgo excepcionalmente elevado de ser objeto de violencia indiscriminada, en una situación de conflicto armado, y que no puedan volver a ese tercer país" ${ }^{40}$.

\section{4. Otras posibles alternativas de alcance restringido para los Migrantes Climáticos. La Directiva 2009/50/CE y la Directiva 2014/36/UE.}

Ante la falta de reconocimiento y de protección expresa de los migrantes climáticos en el ámbito del SECA, nos preguntamos sobre las posibilidades que ofrece la política de la UE de inmigración.

En este sentido, por un lado, la Directiva 2014/36/UE del Parlamento Europeo y del Consejo de 26 de febrero de 2014 sobre las condiciones de entrada y estancia de nacionales de terceros países para fines de empleo como trabajadores temporeros también podría constituir una solución temporal para los migrantes climáticos en periodos estacionales de mayor vulnerabilidad $^{41}$. Si bien, al igual que apuntamos en relación a la Directiva de Protección Temporal, no ofrece una solución definitiva para los mismos.

Asimismo, por otro lado, los nacionales de terceros Estados que se ven forzados a migrar como consecuencia del cambio climático que logren encajar dentro del perfil de trabajadores altamente cualificados,

${ }^{38}$ Meltem, Ineli-Ciger (2020), What a difference two decades make? The shift from temporary to immediate protection in the new European Pact on Asylum and Migration. Disponible en: https://eumigrationlawblog.eu/what-a-difference-twodecades-make-the-shift-from-temporary-to-immediate-protection-in-the-neweuropean-pact-on-asylum-and-migration/\#more-3339 (ultimo acceso: 14.06.2021); Liguori, Chiara (2021), “The response of ...” op. cit., p. 20.

39 Liguori, Chiara (2021), “The response of ...” op. cit., p. 20.

${ }^{40}$ Art. 10 de la Propuesta de Reglamento del Parlamento Europeo y del Consejo relativo a las situaciones de crisis y de fuerza mayor en el ámbito de la migración y el asilo COM (2020) 613 final.

41 Abellán, Beatriz (2020), ¿Protege el Marco Jurídico Europeo a los Migrantes Climáticos? Disponible en: https://migracionesclimaticas.org/protege-el-marcojuridico-europeo-a-los-migrantes-climaticos/ (último acceso: 14.06.2021). 
podrían beneficiarse del sistema establecido por la Directiva 2009/50/CE -mediante la que se crea la Tarjeta Azul de la UE-. Un sistema, que sin embargo es muy restringido en términos de admisión ${ }^{42}$.

Y es que, como señala la doctrina, podemos decir que, en general, las normas de la UE sobre entrada y residencia parece que están centradas en ciertos grupos específicos de migrantes, principalmente trabajadores altamente cualificados, estudiantes, investigadores científicos y trabajadores de temporada ${ }^{43}$. Sin embargo, importantes categorías de migrantes-trabajadores procedentes de terceros Estados como los trabajadores no estacionales de cualificación media-bajaquedarían fuera del paraguas de estas Directivas, al menos, en términos de condiciones de admisión ${ }^{44}$. Además, como señala Solanes Corella ${ }^{45}$, la gestión en la práctica de los flujos migratorios de nacionales de terceros países en la UE que entran de forma legal descansa principalmente en las necesidades laborales del momento, lo cual no siempre es posible ni eficaz y se suele circunscribir únicamente a determinados sectores de trabajo. Por todo ello, podemos concluir que dichas Directivas tampoco ofrecen una solución efectiva y concreta para los migrantes climáticos.

Sistemas similares a los que acabamos de indicar también los encontramos en el ámbito del pacífico, donde existen diversos mecanismos como el Pacific Access Category ${ }^{46}$ y el Pacific Labour

${ }^{42}$ Conviene señalar que dicha Directiva está siendo actualmente objeto de revisión. En este sentido, el Parlamento Europeo y el Consejo recientemente alcanzaron un acuerdo el 17 de mayo de 2021 que, a priori, anunció la adopción de requisitos de admisión más flexibles.

${ }^{43}$ Liguori, Chiara (2021), “The response of ...” op. cit., p. 17.

${ }^{44}$ SWD (2019) 1055 final Part 1/2 Commission Staff Working Document Fitness Check on EU Legislation on legal migration, pp. 100-101. Asimismo, Vid. Liguori, Chiara (2021), “The response of ...” op. cit., pp. 17-18.

45 Solanes Corella, Ángeles (2021), "Desplazados y Refugiados Climáticos. La Necesidad de Protección por Causas Medioambientales” Anales de la Cátedra Francisco Suárez núm. 55, pp. 443-444.

46 Acuerdo de migración planificada entre Nueva Zelanda y las pequeñas Islas del pacífico que permite a un determinado número de habitantes de las mismas la posibilidad de residir de forma permanente en aquella a un determinado número. Se trata de un sistema restringido, dado que los flujos migratorios están sujetos a una cuota anual de entrada (variable en función del país de origen) y al cumplimiento de determinados requisitos (de edad, empleabilidad, conocimiento de idiomas, estado de salud...). 
Scheme $e^{47}$, de los que se pueden beneficiar los habitantes de los pequeños Estados Insulares en riesgo de desaparecer como consecuencia de la subida del nivel del mar derivada de los efectos del Cambio Climático (como Kiribati, Tuvalu, Fiji...), pero que se tratan de opciones restringidas que abarcan un número reducido de beneficiarios y tampoco parecen ofrecer una solución definitiva y específica para los migrantes climáticos.

\section{5. El Nuevo pacto sobre Migración y Asilo}

También conviene hacer referencia al nuevo Pacto sobre Migración y Asilo propuesto por la Comisión Europea en $2020^{48}$ y exponer las posibles implicaciones que podría tener sobre los migrantes climáticos.

La principal novedad que aporta la Propuesta radica en la sustitución del sistema de cuotas obligatorias de reparto de los solicitantes de protección internacional entre los diferentes Estados Miembros en función de criterios objetivos -propuesto con motivo de la crisis migratoria de 2015- por un "mecanismo de solidaridad obligatoria”. Este nuevo sistema ofrecería a los Estados que no quieran acoger a los solicitantes de asilo la posibilidad de optar por la adopción de otras alternativas, principalmente mediante el denominado "patrocino de retorno", consistente en ayudar a devolver rápidamente a aquellos nacionales de terceros países que se encuentran en otro Estado de la UE sin tener derecho a permanecer, así como por medio de la prestación de asistencia financiera encaminada a mejorar la capacidad de recepción de desplazados por parte de otros Estados Miembros (por ejemplo, ayudando a construir un campo para refugiados).

En general, las medidas propuestas por la Comisión en el nuevo Pacto han recibido voces críticas entre numerosos autores, que hablan de una solidaridad "a la carta" ${ }^{49}$ y de una "involución" 50 . Asimismo,

${ }^{47}$ Acuerdo para trabajar en el sector agrícola en Australia de forma temporal, firmado con los pequeños Estados del Pacífico.

${ }^{48}$ Comunicación de la Comisión relativa al Nuevo Pacto sobre Migración y Asilo COM (2020) 609 final.

${ }^{49}$ Vid., Inter alia, Manchón Campillo, Felipe (2020), “El Pacto sobre Migración y Asilo ¿Una Nueva Oportunidad para Europa?” bie3: Boletín IEEE, 20, p. 670. Y es que, como señala Faggiani, el nuevo mecanismo propuesto otorga una discrecionalidad excesiva por parte de los Estados Miembros. Faggiani, Valentina (2020), “¿Hacia 
diversas ONGs definen el Pacto como una “decepción” y una "oportunidad perdida”, entendiendo que el mismo se encamina más hacia facilitar el retorno y la externalización de fronteras que en brindar una protección a migrantes y refugiados ${ }^{51}$.

En el caso concreto de los migrantes climáticos, si bien el Pacto expresamente reconoce las repercusiones que tiene el cambio climático en las migraciones, no identifica mecanismos claros para facilitar la movilidad de quienes podrían estar en riesgo de desplazamiento debido a los impactos que se derivan del mismo ${ }^{52}$.

Además de ello -como hemos apuntado anteriormente-, al prever dicho Pacto la sustitución de la Directiva de Protección Temporal por un Reglamento de Protección Inmediata cuyo artículo 10 establece unos criterios de selección más estrictos, ello dificultaría aún más la incardinación de los migrantes climáticos dentro de los desplazados que podrían ser beneficiarios de dicha salvaguarda.

\section{APLICACIÓN DEL PRINCIPIO DE NO DEVOLUCIÓN (O DE NON REFOULEMENT) A LOS MIGRANTES CLIMÁTICOS}

El Principio de no devolución es considerado a nivel doctrinal como un Principio de Derecho Internacional General consuetudinario, así como una norma imperativa o de Ius Cogens. Está recogido en diversos textos internacionales ${ }^{53}$ y regionales ${ }^{54} \mathrm{y}$, en términos generales, viene a prohibir a los Estados la devolución, expulsión o extradición de una persona

una Reforma Integral o solo Aparente y más Involutiva del Sistema Europeo Común de Asilo?” Revista General de Derecho Europeo 52, pp. 21 y 39.

${ }^{50}$ Faggiani, Valentina (2020), “¿Hacia una Reforma...” op. cit., p. 39.

${ }^{51}$ Vid. Comisión Española de Ayuda al Refugiado (CEAR) (2020): Nuevo Pacto de Migración y Asilo de la UE: cinco claves de una propuesta decepcionante. Disponible en: https://www.cear.es/claves-nuevo-pacto-migracion-asilo/ (último acceso: 10.06.2021). Asimismo, Vid. Felipe Pérez, Beatriz (2020), El papel del Sector Privado... op. cit., p. 15.

${ }^{52}$ Liguori, Chiara (2021), “The response of ...” op. cit., p. 17.

${ }^{53}$ Principalmente, la Convención de Ginebra de 1951 (art. 33) y la Convención contra la Tortura y Otros Tratos o Penas Crueles, Inhumanos o Degradantes (art. 3).

${ }^{54}$ Vid., inter alia, la Convención de Addis Abeba de la Organización para la Unidad Africana de 1969 (art. 2.3); Convención Americana sobre Derechos Humanos (Pacto de San José) (art. 22.8). 
cuando con ello corra el riesgo de sufrir graves violaciones de sus Derechos Humanos.

En el seno del Consejo de Europa, si bien el Principio de nonrefoulement no viene expresamente contemplado en Convenio Europeo para la protección de los Derechos Humanos ${ }^{55}$, el Tribunal Europeo de Derechos Humanos en ciertos pronunciamientos de alguna forma lo ha considerado integrado en varios de sus preceptos, $\mathrm{y}$, en particular dentro el artículo 3, relativo al no sometimiento a Tratos Inhumanos o Degradantes $^{56}$.

En el ámbito de la Unión Europea, el Principio de No Devolución viene reconocido expresamente en la Carta Europea de los Derechos Fundamentales (art. 19.2) ${ }^{57}$, que señala que nadie podrá ser devuelto, expulsado o extraditado a un Estado en el que corra un grave riesgo de ser sometido a (...)tratos inhumanos o degradantes.

${ }^{55}$ Conviene apuntar que, pese a que los Estados Miembros de la UE son parte del Convenio Europeo sobre Derechos Humanos, la UE no forma parte del mismo, ni por tanto está sometida al Tribunal Europeo de Derechos Humanos (TEDH). No obstante, el artículo 6.2 del Tratado de la Unión Europea (TUE) señala que la Unión se adherirá a dicho Convenio, En base a ello, la UE realizó un intento, elaborando un Proyecto de Acuerdo de Adhesión al mismo. Sin embargo, el Tribunal de Justicia de la Unión Europea (TJUE) se ha mostrado contrario por entender que dicho Proyecto de Acuerdo no es compatible con los Tratados de la Unión. En este sentido, Vid. Dictamen 2/13 de 18 de diciembre de 2014 del TJUE. En cualquier caso, el artículo 6.3 del TUE resalta que los Derechos Fundamentales garantizados por el Convenio Europeo para la protección de los Derechos Humanos formarán parte del Derecho de la UE como Principios Generales. Asimismo, el artículo 52.3 de la Carta Europea de los Derechos Fundamentales de la UE otorga con carácter general un sentido y alcance similar a los Derechos recogidos en la Carta y en el Convenio Europeo sobre Derechos Humanos. Es por ello que, como señala Abrisketa, es de esperar que los desarrollos jurisprudenciales del TEDH sean tenidos en cuenta en los ámbitos legislativo y judicial de la UE. Abrisketa Uriarte, Joana (2017), "La dimensión externa del derecho de la Unión Europea en materia de refugio y asilo: un examen desde la perspectiva del non-refoulement" Revista de Derecho Comunitario Europeo, 56, p. 139.

${ }^{56}$ Canosa Usera, Raúl (2018), "La Prohibición de la Tortura y de Penas y Tratos Inhumanos o Degradantes en el CEDH” UNED. Teoría y Realidad Constitucional, 42, p. 263. En este sentido, en la práctica podemos encontrar diversas resoluciones del Tribunal de Estrasburgo como en el caso Soering c. Reino Unido de 7 de Julio de 1989 o el caso Travelsi c. Bélgica de 4 de Septiembre de 2014.

57 También viene recogido en el TFUE (art. 78), así como en diversos textos normativos que integran el Derecho Derivado de la UE, por ejemplo, en la Directiva de Retorno 2008/115/CE (arts. 4, 5 y 9), Directiva de Protección Temporal (art. 3), Directiva de Requisitos (art. 21). 
Aquí, se plantea la siguiente cuestión: pensemos en un migrante climático solicitante de asilo en un país de la UE, cuya solicitud es rechazada por considerarse que no cumple los requisitos necesarios para recibir dicha protección -es decir, no es considerado "refugiado" ni beneficiario de la "protección subsidiaria”- y es devuelto a su país de origen ¿podría considerarse que con ello se le está poniendo en un grave riesgo de sufrir tratos inhumanos o degradantes? ¿los efectos negativos derivados del cambio climático -pensemos en fuertes sequías, falta de agua potable, escasez de tierras fértiles- a los que se va a ver expuesta la persona devuelta pueden llevarle a una situación considerada como un trato inhumano o degradante?

En relación a estos interrogantes, en el plano internacional, la reciente decisión del Comité de Derechos Humanos en el caso Teitiota ${ }^{58}$ ha puesto de manifiesto -pese al no reconocimiento de las peticiones del solicitante- que efectos del cambio climático pueden exponer a las personas a la violación de sus derechos humanos, en particular, su derecho a la vida y a no ser sometidos a tratos crueles, inhumanos $o$ degradantes $^{59}$-, haciendo que entren en juego las obligaciones de no devolución.

En el plano europeo, ni el TJUE -en relación a la Carta Europea de los Derechos Fundamentales- ni el TEDH -en relación al Convenio Europeo para la Protección de los Derechos Humanos- se han pronunciado en relación a este extremo en el caso particular de los migrantes climáticos. Si bien, en la Jurisprudencia del Tribunal de Estrasburgo encontramos algunos casos que pueden ser de interés a la hora de concretar qué entiende el Tribunal por tratos crueles, inhumanos $y$ degradantes $^{60}$. En este sentido, podemos citar el caso D.C. c. Reino Unido, de 2 mayo de 1997, en el que interpreta que el envío de un extranjero a un tercer Estado, cuando ello suponga un riesgo real de muerte en las condiciones más preocupantes, constituye un tratamiento inhumano (párrafo 53). En este caso, el riesgo venía de las malas condiciones hospitalarias del país donde iba a ser enviado, que podían comprometer su mal estado de salud. Pero, pensemos en un migrante

${ }^{58}$ Vid. CCPR/C/127/D/2728/2016 Dictamen de 23 de septiembre de 2020 (párrafo 9.11).

${ }^{59}$ Vid. Artículos 6 y 7 del Pacto Internacional de los Derechos Civiles y Políticos.

${ }^{60}$ Volvemos a recordar el interés que tiene la jurisprudencia del TEDH en esta materia, dado que puede llegar a ser considerada en los ámbitos legislativo y judicial de la UE. 
climático que, al ser devuelto a su país de origen, se vea abocado a enfrentarse a enfermedades, hambruna y falta de agua potable como consecuencia de los efectos derivados del cambio climático ${ }^{61}$, no pudiendo dicho país hacer frente a los mismos con medidas de adaptación adecuadas -dada su escasez de recursos-. ¿implicaría ello un riesgo para su vida $\mathrm{y}$, en definitiva, un tratamiento inhumano o degradante? Podría llegar a interpretarse que sí. Sin embargo, podemos observar cómo el TEDH adopta en su interpretación de tratos inhumanos o degradantes un criterio estricto -recordemos la expresión, riesgo real de muerte en las condiciones más preocupantes- que parece abarcar únicamente aquellos casos que revistan una extrema gravedad y excepcionalidad $^{62}$. En este sentido, como apunta McAdam:

Los tribunales han circunscrito cuidadosamente el significado de "trato inhumano o degradante", por lo que no se puede usar como un remedio para la pobreza general, el desempleo o la falta de recursos o de atención médica, excepto en las circunstancias más excepcionales ${ }^{63}$.

Por otro lado, sí que encontramos en el ámbito nacional de los Estados Miembros algún caso en el que los Tribunales dictaminaron la no devolución de un ciudadano extranjero fundamentándose en causas ambientales, lo que podría abrir la puerta a considerar en un futuro la no devolución de los migrantes climáticos, siendo paradigmática reciente la sentencia de un Tribunal Francés que impidió la expulsión de un ciudadano de Bangladesh a su país de origen, por entender que ello podría suponer un peligro para su vida, dada la tasa tal elevada de contaminación del aire en el mismo (si bien, es cierto que pesó

61 Eventos extremos, falta de productividad de las tierras, sequías, inundaciones ocasionadas por la subida del nivel del mar ...

62 Así también lo entienden De Moor y Cliquet, que sitúan la gravedad de la perturbación ambiental como uno de los principales elementos determinantes a la hora de considerar de un desplazado por causas ambientales -como podría ser un migrantes climático- está protegido por el Principio de no Retorno, de conformidad con la interpretación adoptada por el TEDH en otras decisiones relativas a la aplicación del artículo 3 del Convenio Europeo de Derechos Humanos. De Moor, Nicole y Cliquet, An (2012), Environmenyal Displacement...” op. cit., p. 7.

${ }^{63}$ McAdam, Jane (2010), “El Desplazamiento Provocado...”, op. cit., p. 5. En este mismo sentido, Abellán señala que hasta ahora, el Tribunal de Estrasburgo ha sido restrictivo en equiparar vulnerabilidades socio-económicas a trato inhumano o degradante. Abellán, Beatriz (2020), ¿'Protege el Marco... op. cit. 
especialmente en el resultado final de la decisión la patología crónica asma- que éste nacional extranjero padecía) ${ }^{64}$.

\section{CONCLUSIONES}

A lo largo del presente trabajo hemos llegado a la conclusión general de que el Derecho Derivado de la Unión Europea, si bien no aborda directamente la cuestión de los migrantes climáticos, posee ciertos mecanismos -principalmente en el ámbito del SECA- que, desarrollando una interpretación extensiva y amplia -y quizá un tanto forzada- de los mismos, podríamos considerar que de alguna forma pueden abarcar bajo su paraguas de protección a los nacionales originarios de terceros Estados que se ven forzados a desplazarse como consecuencia de los efectos derivados del cambio climático. Nos referimos en particular a la protección subsidiaria brindada por la Directiva de Requisitos (mayores dificultades encontrarían para ser considerados amparados por el estatuto de "refugiados") y a la prevista por la Directiva sobre Protección Temporal. Tampoco se puede excluir la idea de que ciertos colectivos de migrantes climáticos puedan recurrir como solución indirecta a la posibilidad de residir legalmente en la Unión Europea bajo el paraguas de las Directivas que regulan la entrada y estancia de extranjeros para determinados fines de empleo.

Sin embargo, en cualquier caso, se trataría en general de soluciones limitadas que no ofrecen una respuesta específica y definitiva para el problema que están sufriendo estas personas. Bien porque constituyen una solución provisional (como en el caso de la protección otorgada por la Directiva sobre protección temporal), bien porque restringen su ámbito de aplicación únicamente a determinados subgrupos (en particular, temporeros y trabajadores altamente cualificados). Por otro lado, las propuestas presentadas por la Comisión en el Nuevo Pacto sobre Migración y Asilo tampoco parecen ofrecer soluciones concretas para los Migrantes Climáticos y, en términos generales, han suscitado cierto recelo entre la doctrina y las ONGs.

Por último, tomando como referencia los tímidos "avances” que se van dando en el plano internacional sobre esta cuestión (como lo es el

\footnotetext{
64 Información disponible en: https://www.climaterefugees.org/spotlight/2021/1/15/french-court (último acceso: 21.06.2021).
} 
reconocimiento por el Comité de los Derechos Humanos de la ONU de que los efectos del cambio climático pueden llegar a vulnerar los derechos humanos, desencadenando la obligación de no devolución de un extranjero a su país de origen), encontramos en la aplicación del Principio de non-refoulement (Principio de Derecho Internacional General Consuetudinario, recogido en la Carta Europea de los Derechos Fundamentales) una garantía para los desplazados climáticos, especialmente si, llevándose cabo una interpretación amplia, se entiende que la expulsión de los mismos les pondría en un grave riesgo de sufrir tratos inhumanos o degradantes.

En definitiva, entendemos que en la actualidad el Derecho de la Unión Europea únicamente ofrece una salvaguarda limitada para los migrantes climáticos, a la que pueden intentar acogerse mediante la aplicación indirecta de la normativa existente y realizando malabares con la hermenéutica. Por ello, ponemos de manifiesto la necesidad de ir más allá y desarrollar una regulación a nivel comunitario que aborde el problema de las personas provenientes de terceros Estados que se ven forzadas a migrar a territorio europeo huyendo de los impactos derivados del cambio climático, y que, hoy en día no cuentan con un instrumento normativo que les ofrezca una protección expresa y definitiva.

\section{BiBLIOGRAFÍA}

ACNUR (UNHCR) (2020), Legal considerations regarding claims for international protection made in the context of the adverse effects of climate change and disasters, 1 October 2020, pp. 1-11. Disponible en: https://www.refworld.org/docid/5f75f2734.html (último acceso: 02.06.2021).

Abel, Guy, Brottrager, Michael, Crespo Cuaresma, Jesus y Muttarak, Raya (2019), "Climate, conflict and forced migration" Global Environmental Change, Volume 54, 2019, pp. 239-249.

Abellán, Beatriz (2020), ¿Protege el Marco Jurídico Europeo a los Migrantes Climáticos?

Disponible en: 
https://migracionesclimaticas.org/protege-el-marco-juridicoeuropeo-a-los-migrantes-climaticos/ (último acceso: 14.06.2021).

Abrisketa Uriarte, Joana (2017), “La dimensión externa del derecho de la Unión Europea en materia de refugio y asilo: un examen desde la perspectiva del non-refoulement" Revista de Derecho Comunitario Europeo, 56, pp. 119-158. doi: https://doi.org/10.18042/cepc/rdce.56.04

Amado Gomes, Carla (2014), "Migrantes climáticos - Para além da Terra Prometida”, Congresso de Direitos Humanos, 20 a 22 de Novembro de 2013, pp. 1-17. Disponible en: https://www.icjp.pt/sites/default/files/papers/palmas.pdf (último acceso: 02.06.2021).

Canosa Usera, Raúl (2018), “La Prohibición de la Tortura y de Penas y Tratos Inhumanos o Degradantes en el CEDH” UNED. Teoría y Realidad Constitucional, 42, pp. 247-271

De Moor, Nicole y Cliquet, An (2012), Environmenyal Displacement: $a$ New Challenge for European Migration Policy, pp. 1-20. Disponible en: https://biblio.ugent.be/publication/761954/file/784741.pdf

Espósito, Carlos y Torres Camprubí, Alejandra (2012), “Cambio Climático y Derechos Humanos: El desafío de los 'nuevos refugiados"” Revista de Derecho Ambiental de la Universidad de Palermo, 1, pp. 7-32.

Faggiani, Valentina (2020), “¿Hacia una Reforma Integral o solo Aparente y más Involutiva del Sistema Europeo Común de Asilo?” Revista General de Derecho Europeo 52, pp. 1-39.

Felipe Pérez, Beatriz, Iglesias Márquez, Daniel y Villavicencio Calzadilla, Paola (2019), "Migraciones climáticas: el papel de los derechos humanos para superar el persistente vacío jurídico" Revista Latinoamericana de Derechos Humanos, 30 (1), pp. 15-46. 
La Respuesta Jurídica de la Unión Europea ante las Migraciones Climáticas...137

Felipe Pérez, Beatriz (2020), El papel del Sector Privado Europeo ante las migraciones climáticas. Una propuesta de debida diligencia, pp. $1-52$.

Leal Arcas, Rafael (2012), “Climate migrants: Legal options” International Conference on Emerging Economies - Prospects and Challenges(ICEE-2012). Procedia - Social and Behavioral Sciences 37, pp. $86-96$

Liguori, Chiara (2021), "The response of the European Union to human mobility in the context of climate change" Refugee Law Initiative Working Paper 54, pp. 1-28.

López Ramón, Fernando (2017), "Los Derechos de los Emigrantes Ecológicos”. Cuadernos Manuel Jiménez Abad, pp. 6-18.

Manchón Campillo, Felipe (2020), "El Pacto sobre Migración y Asilo ¿Una Nueva Oportunidad para Europa?” bie3: Boletín IEEE, 20, pp.654-671.

Martín Pascual, Elena (2018), "Migraciones causadas por la subida del nivel del mar: un reto para el Derecho Internacional”. Revista Catalana de dret ambiental Vol. IX Núm 2. pp. 1-32.

McAdam, Jane (2010), "El Desplazamiento Provocado por el Cambio Climático y el Derecho Internacional”. Evento paralelo al Diálogo del Alto Comisionado sobre los desafíos en materia de protección 8 de diciembre de 2010, Palacio de las Naciones, pp. 1-8. Disponible en: https://www.acnur.org/5d5476434.pdf (último acceso 02.06.2021).

Meltem, Ineli-Ciger (2020), What a difference two decades make? The shift from temporary to immediate protection in the new European Pact on Asylum and Migration. Disponible en: https://eumigrationlawblog.eu/what-a-difference-two-decades-makethe-shift-from-temporary-to-immediate-protection-in-the-neweuropean-pact-on-asylum-and-migration/\#more-3339 (ultimo acceso: 14.06.2021). 
Pérez Villalobos, María Concepción (2017), "La Crisis de los Refugiados y el Derecho de Asilo en la Unión Europea” Anales de Derecho, 1, pp. 1-25.

Prieur, Michel., s.f., Draft Convention on the International Status of Environmentally-Displaced Persons, pp. 1-10. Disponible en: https://unfccc.int/files/adaptation/groups_committees/loss_and_dama ge_executive_committee/application/pdf/prieur-

convention_on_the_international_status_of_environmentally.pdf Último acceso: 02.06.2021.

Solanes Corella, Ángeles (2021), "Desplazados y Refugiados Climáticos. La Necesidad de Protección por Causas Medioambientales” Anales de la Cátedra Francisco Suárez núm. 55, pp. 433-460 ISSN 00087750 http://dx.doi.org/10.30827/ACFS.v55i0.15534

The Greens in the European Parliament (2013), Position Paper Climate Change, Refugees and Migration. Disponible en: https://europeangreens.eu/sites/europeangreens.eu/files/news/files/Gr eens\%20EFA\%20-\%20Position\%20Paper\%20-

\%20Climate\%20Change\%20Refugees\%20and\%20Migration.pdf (último acceso: 02.06.2021).

UNEP (2020), Emissions Gap Report, pp 1-101. ISBN: 978-92-8073812-4. Disponible en: https://www.unep.org/es/emissions-gapreport-2020 (último acceso: 02.06.2021). 